\title{
A Real-World Study of 30-Day Exacerbation Outcomes in Chronic Obstructive Pulmonary Disease (COPD) Patients Managed with Aerobika OPEP
}

\author{
Chakkarin Burudpakdee · Arpamas Seetasith • Patrick Dunne • \\ Garry Kauffman · Brian Carlin · Dom Coppolo · Jason Suggett
}

Received: January 4, 2017 / Published online: February 6, 2017

(C) The Author(s) 2017. This article is published with open access at Springerlink.com

\begin{abstract}
Introduction: Oscillating positive expiratory pressure (OPEP) devices may reduce chronic symptoms in patients with obstructive pulmonary disease (COPD); however, no real-world
\end{abstract}

Enhanced content To view enhanced content for this article go to http://www.medengine.com/Redeem/ E587F06068790517.

Electronic supplementary material The online version of this article (doi:10.1007/s41030-017-0027-5) contains supplementary material, which is available to authorized users.

C. Burudpakdee $(\bowtie) \cdot$ A. Seetasith

QuintilesIMS, Fairfax, VA, USA

e-mail: chakkarin.burudpakdee@quintilesims.com

C. Burudpakdee

University of North Carolina at Charlotte,

Charlotte, NC, USA

P. Dunne

HealthCare Productions Inc., Fullerton, CA, USA

G. Kauffman

Kauffman Consulting, Walnut Cove, NC, USA

B. Carlin

Sleep Medicine and Lung Health Consultant, Pittsburg, PA, USA

D. Coppolo

Monaghan Medical Corporation, Syracuse, NY, USA

J. Suggett

Trudell Medical International, London, ON, Canada studies have been performed to evaluate the benefits of these devices. The objective of this study was to measure the rate of early (30-day) moderate-to-severe exacerbations and related costs in COPD patients treated with Aerobika, an OPEP device, vs. a matched control group in a real-world setting.

Methods: The study utilized data from the QuintilesIMS' CDM hospital database. COPD patients treated with Aerobika OPEP between 9/2013 and 8/2015 were propensity score matched to COPD patients who did not use any positive expiratory pressure device. Severe exacerbation was defined as a hospital admission with a diagnosis for chronic bronchitis or COPD. Moderate-to-severe exacerbation was defined as a hospitalization or an ED visit with a diagnosis for chronic bronchitis or COPD. Exacerbations and costs were compared between cohorts at 30 days. A generalized linear model (GLM) was used to estimate the marginal effect of Aerobika OPEP on the cost of ED visits and hospitalizations due to COPD exacerbations.

Results: A total of 405 Aerobika OPEP patients were matched to 405 controls. At 30 days, $18.5 \%$ of subjects using the Aerobika OPEP vs. $25.7 \%$ of controls had a moderate-to-severe exacerbation $(p=0.014) ; 13.8 \%$ of subjects with Aerobika OPEP vs. $19.0 \%$ of controls had a severe exacerbation $(p=0.046)$. The mean per patient cost of moderate-to-severe exacerbations and severe exacerbations in the Aerobika 
OPEP group was significantly lower than controls ( $\$ 2975$ vs. $\$ 6065 ; p=0.008$, and $\$ 2838$ vs. $\$ 5871 ; p=0.009$, respectively). In the GLM, the per-patient cost of moderate-to-severe exacerbations in the Aerobika OPEP group was 34\% lower $(p=0.012)$ than the control group.

Conclusions: Study findings suggest that using Aerobika OPEP as part of a treatment regimen may help reduce ED visits, hospital re-admissions and related costs in COPD patients who have a history of exacerbations.

Keywords: COPD; Exacerbations; PEP; OPEP

\section{INTRODUCTION}

Chronic obstructive pulmonary disease (COPD) is a major source of morbidity, mortality, and costs. The biggest driver of these healthcare costs is hospitalization [1]. COPD affects approximately $5 \%$ of the US adult population and is often associated with exacerbations [2-4]. Acute exacerbations are the most frequent causes for medical visits, hospital admissions, early readmissions, and death in patients with COPD [5]. It is predicted that by 2030, COPD-related hospitalization will increase by $210 \%$ compared to 2010 levels [6]. Of note, one out of five patients hospitalized for a COPD exacerbation required re-hospitalization within 30 days [7]. During an exacerbation, airways are compromised by inflammation and mucus build up, which, in turn, increase lung hyperinflation [8]. Many COPD patients experience two to three exacerbations every year, suggesting a continued need to manage their disease [9-11].

According to GOLD guidelines, smoking cessation agents, pharmacologic therapy, and rehabilitation are currently recommended for the treatment of COPD [12]. Drug-free airway clearance methods such as oscillating positive expiratory pressure (OPEP) have been proposed to provide benefit in COPD patients though opening and vibrating airways and mobilizing bronchial secretions with increased sputum [13]. Aerobika (TMI, London, ON) is a handheld mechanical OPEP device where patients exhale against a manually adjusted variable resistance. Aerobika has been shown to significantly improve forced vital capacity (FVC), 6-min walk distance (6MWD), and St. George's Respiratory Questionnaire (SGRQ) score in COPD patients [14]. However, the effectiveness of an OPEP device, such as Aerobika, in reducing the COPD exacerbations has not been studied in a real-world setting. The purpose of this study was to measure the rate of moderate-to-severe early (30-day) COPD exacerbations and related costs.

\section{METHODS}

This retrospective database study utilized patient data from January 1, 2011 to September 30, 2015 in the QuintilesIMS CDM hospital database. The database consists of over 650 US hospitals covering 7 million inpatient stays and 60 million outpatient visits each year. Patientlevel data include healthcare services from hospital departments (inpatient, outpatient clinic, emergency department, pharmacy), and ICD-9-CM diagnosis codes and CPT procedure codes associated with each encounter. Information on drugs and devices dispensed are reported in text fields in the database. Detailed charges associated with each visit, dispensed medication, and dispensed devices are also reported in the database. All patient-level data were anonymized and de-identified in compliance with the Health Insurance Portability and Accountability Act (HIPAA).

Patients treated with Aerobika OPEP between September 1, 2013 and August 31, 2015 (i.e., selection window) were selected into the study; the index date was defined as the first date of Aerobika OPEP provided after a hospital visit or admission. Aerobika OPEP use was identified using the text field billing description. Aerobika OPEP patients were then required to have at least one hospital patient record before index date, have at least one hospital patient record after index date (to ensure they remained in the database), have a diagnosis of chronic bronchitis (ICD-9-CM 491.xx) on or before their index date, and be at least 18 years of age. Patients were excluded if they had evidence of Aerobika OPEP before their index date, were treated with any positive expiratory pressure device or 
non-index OPEP device (e.g., other than Aerobika OPEP) at any time in the observational period, or had incomplete demographic data (age, gender, payer type, geographic region).

In order to measure the benefit of Aerobika OPEP, a control group of similar COPD patients without treatment with any (oscillating or non-oscillating) positive expiratory pressure device was selected. Patients with a diagnosis of chronic bronchitis between September 1, 2013 and August 31, 2015 (i.e., selection window) were selected into the control group; the index date was defined as the first date of diagnosis, associated with a hospital visit/admission, in the selection window. Controls were then required to have at least one patient record before the index date, have at least one patient record after the index date, and be at least 18 years of age. Patients were excluded if they were treated with any positive expiratory pressure device or OPEP device at any time in the observational period, or had incomplete demographic data (age, gender, payer type, geographic region).

Once the selection of control patients was complete, controls were propensity score (PS) matched to Aerobika OPEP patients at a 1:1 ratio using the greedy nearest-neighbor matching algorithm, without replacement. PS matching used a logit regression constructed from baseline patient characteristics measured during the 12 months before index date. This methodology is commonly used in observational studies since it mimics the selection process of randomized clinical trials and decreases bias in estimation of treatment effects between comparison groups [15]. Variables used in the PS match included age, gender, payer type, Charlson Comorbidity Index (CCI), comorbid conditions (acute respiratory tract infections, anxiety/depression, asthma, bronchiectasis, cardiovascular disease, diabetes, emphysema, hyperlipidemia, hypothyroidism, malignancy, and stroke or transient ischemic attack), medication history (inhaled corticosteroids + long-acting beta agonists combination (ICS/LABA), long-acting muscarinic antagonists (LAMA), oral corticosteroids (OCS), short-acting beta agonist (SABA), and short-acting beta agonists + short-acting muscarinic antagonists combination (SABA/SAMA), SAMA, xanthines, antibiotics), type of visit on index date (inpatient, ED, outpatient), history of exacerbations in the year prior the study, and year of index.

Early moderate-to-severe and severe exacerbations were measured at 30 days post index and were defined based on healthcare resource utilization, similar to previously published database studies $[16,17]$. A moderate-to-severe exacerbation was defined as the occurrence of either a hospitalization or an ED visit with a diagnosis for chronic bronchitis or COPD (ICD-9-CM: 491.xx, 492.xx, 496.xx). A severe exacerbation, a subset of the moderate-to-severe category, was defined as a hospitalization with a diagnosis of chronic bronchitis or COPD (ICD-9-CM: 491.xx, 492.xx, 496.xx). Exacerbation events were reported per patient and as a proportion of patients with an exacerbation. Additionally, the cost of moderate-to-severe and severe exacerbations per patient was measured at 30 days post index. CDM data consists of charges for healthcare services; therefore, a cost-to-charge ratio of 0.4868 was used to convert charges to estimated costs. The ratio was calculated based on the average cost-to-charge ratios published in the Healthcare Cost and Utilization Project's (HCUP) cost-to-charge ratio files for the 2013 National Inpatient Sample (NIS) [18]. Acute care drug usage (oral corticosteroids and antibiotics) during the 30-day post index period was also reported as supporting data.

Baseline patient characteristics were reported using descriptive statistics. Treatment outcomes in the Aerobika OPEP and control groups were compared using bivariate Chi-square tests, and the difference in sample means between the two groups was compared using Student's $t$ test of independent samples. The marginal effect of Aerobika OPEP on per-patient costs for exacerbation was measured using generalized linear models (GLM) with a log link and gamma family distribution in the unmatched population, with covariate adjustments to control for potential confounders. Covariate adjustments for the GLM were made with baseline patient characteristics including age categories, gender, payer type, CCI categories, comorbid conditions, time from first CDM record to index date, 
and history of COPD medication use. All analyses were conducted using SAS 9.4 (Cary, NC, USA). As a retrospective cohort analysis of HIPAA compliant de-identified patient data, no Institutional Review Board IRB review was required for this study.

\section{RESULTS}

Seven hundred and seventy-one patients were identified with Aerobika OPEP within the selection window (Table 1). After applying the selection criteria, the study sample comprised 426 Aerobika OPEP patients. After PS matching, a total of 405 Aerobika OPEP patients and 405 controls were identified; both cohorts were balanced on all baseline characteristics (all $p$ values $>0.05$ ). The mean age of patients was 67 years, most patients were female, and had Medicare as the primary payer (Table 2). The most common comorbid conditions were hyperlipidemia $(\geq 66.4 \%)$, anxiety/depression ( $\geq 53.6 \%)$, cardiovascular disease $(\geq 47.1 \%)$, and diabetes $(\geq 40.7 \%)$. History of all-cause hospitalizations and all-cause ED visits in the 12 months prior to index date were similar between Aerobika OPEP patients and matched controls; the proportions of patients with all-cause hospitalizations were 73.8 and $73.6 \%$, respectively. History of treatments was similar between the two cohorts; the most common treatments were SABA, SABA + SAMA, antibiotics, and ICS/LABA.

At 30 days, the proportion of patients with a moderate-to-severe exacerbation was significantly lower in the Aerobika OPEP cohort compared to matched controls (18.5 and $25.7 \%$, $p=0.014$, respectively) (Table 3 ). The mean number of moderate-to-severe exacerbations per patient was $0.23(\mathrm{SD} \pm 0.56)$ in the Aerobika OPEP group vs. $0.30(\mathrm{SD} \pm 0.55)$ in the matched control group $(p=0.099)$. In terms of severe exacerbations, the proportion of patients with a severe exacerbation was significantly lower for the Aerobika OPEP cohort compared to matched controls (13.8 and 19.0\%, $p=0.046$ ). The mean number of severe exacerbations per patient was also significantly lower in Aerobika OPEP $[0.15$ (SD \pm 0.40$)$ vs. 0.21 (SD: \pm 0.45 ), $p=0.048$, respectively].

Healthcare costs at 30 days were lower in Aerobika OPEP; the mean cost of moderate-to-severe exacerbations per patient was $\$ 2975$ [SD $\pm \$ 11,529$ ] in the Aerobika OPEP cohort compared to $\$ 6065$ [SD $\pm \$ 20,275]$ in

Table 1 Selection of patients with Aerobika OPEP

\begin{tabular}{|c|c|c|c|c|}
\hline \multirow[t]{2}{*}{ Selection criteria } & \multicolumn{2}{|c|}{ Excluded } & \multicolumn{2}{|c|}{ Remaining } \\
\hline & $\bar{N}$ & $\%$ & $\bar{N}$ & $\%$ \\
\hline \multicolumn{5}{|l|}{ Inclusion criteria } \\
\hline $\begin{array}{l}\text { With documentation of Aerobika OPEP use between September 1, } 2013 \text { and August 31, } \\
2015\end{array}$ & - & - & 771 & $100.0 \%$ \\
\hline With $\geq 1$ patient record any time before Aerobika OPEP use & 52 & $6.7 \%$ & 719 & $93.3 \%$ \\
\hline With $\geq 1$ patient record any time after Aerobika OPEP use & 112 & $14.5 \%$ & 607 & $78.7 \%$ \\
\hline With chronic bronchitis diagnosis before or on index date & 49 & $6.4 \%$ & 558 & $72.4 \%$ \\
\hline At least 18 years of age & 0 & $0.0 \%$ & 558 & $72.4 \%$ \\
\hline Without Aerobika OPEP before index date & 0 & $0.0 \%$ & 558 & $72.4 \%$ \\
\hline Without PEP or other OPEP device at anytime & 132 & $17.1 \%$ & 426 & $55.3 \%$ \\
\hline Without incomplete demographic data (age, gender, payer type, geographic region) & 0 & $0.0 \%$ & 426 & $55.3 \%$ \\
\hline Matched Aerobika OPEP patients & & & 405 & \\
\hline
\end{tabular}


Table 2 Baseline patient characteristics

\begin{tabular}{|c|c|c|c|c|c|}
\hline \multirow{2}{*}{$\begin{array}{l}\text { Measures } \\
\text { Demographic characteristics }\end{array}$} & \multicolumn{2}{|c|}{$\begin{array}{l}\text { Aerobika OPEP } \\
N=405\end{array}$} & \multicolumn{2}{|c|}{$\begin{array}{l}\text { Matched controls } \\
N=405\end{array}$} & \multirow[t]{2}{*}{$p$ value } \\
\hline & & & & & \\
\hline Age in years (mean, SD) & 67.1 & \pm 11.4 & 67.7 & \pm 11.9 & 0.435 \\
\hline \multicolumn{6}{|l|}{ Gender $(n, \%)$} \\
\hline Female & 224 & 55.3 & 233 & 57.5 & \multirow[t]{2}{*}{0.523} \\
\hline Male & 181 & 44.7 & 172 & 42.5 & \\
\hline \multicolumn{6}{|l|}{ Payer type $(n, \%)$} \\
\hline Commercial & 30 & 7.4 & 31 & 7.6 & \multirow[t]{4}{*}{0.187} \\
\hline Medicaid & 32 & 7.9 & 19 & 4.7 & \\
\hline Medicare & 236 & 58.3 & 258 & 63.7 & \\
\hline Other & 107 & 26.4 & 97 & 23.9 & \\
\hline \multicolumn{6}{|l|}{ Clinical characteristics } \\
\hline CCI (mean, SD) & 4.4 & \pm 2.7 & 4.7 & \pm 2.7 & 0.090 \\
\hline \multicolumn{6}{|l|}{ Comorbidities $(n, \%)$} \\
\hline Acute respiratory tract infections & 95 & 23.5 & 102 & 25.2 & 0.566 \\
\hline Anxiety/depression & 221 & 54.6 & 217 & 53.6 & 0.778 \\
\hline Asthma & 123 & 30.4 & 131 & 32.3 & 0.545 \\
\hline Bronchiectasis & 8 & 1.9 & 7 & 1.7 & 0.794 \\
\hline Cardiovascular disease & 191 & 47.2 & 204 & 50.4 & 0.361 \\
\hline Diabetes & 165 & 40.7 & 170 & 41.9 & 0.721 \\
\hline Emphysema & 63 & 15.5 & 65 & 16.0 & 0.847 \\
\hline Hyperlipidemia & 269 & 66.4 & 290 & 71.6 & 0.111 \\
\hline Hypothyroidism & 90 & 22.2 & 84 & 20.7 & 0.608 \\
\hline Malignancy & 165 & 40.7 & 165 & 40.7 & 1.000 \\
\hline Stroke or TIA & 29 & 7.2 & 21 & 5.2 & 0.243 \\
\hline Time from first CDM record to index (mean, SD) & 1076.1 & \pm 389.7 & 1141.5 & \pm 332.5 & 0.010 \\
\hline All-cause hospitalizations & 299 & 73.8 & 298 & 73.5 & 0.936 \\
\hline \multicolumn{6}{|l|}{ History of medication use } \\
\hline ICS/LABA & 143 & 35.3 & 145 & 35.8 & 0.883 \\
\hline LAMA & 27 & 6.7 & 25 & 6.2 & 0.774 \\
\hline SABA & 248 & 61.2 & 233 & 57.5 & 0.283 \\
\hline SABA/SAMA & 240 & 59.3 & 226 & 55.8 & 0.320 \\
\hline SAMA & 8 & 1.9 & 10 & 2.5 & 0.633 \\
\hline
\end{tabular}


Table 2 continued

\begin{tabular}{|c|c|c|c|c|c|}
\hline \multirow{2}{*}{$\begin{array}{c}\text { Measures } \\
\text { Xanthines }\end{array}$} & \multicolumn{2}{|c|}{$\begin{array}{l}\text { Aerobika } \\
\operatorname{OPEPN}=405\end{array}$} & \multicolumn{2}{|c|}{$\begin{array}{l}\text { Matched } \\
\text { controls } N=405\end{array}$} & \multirow{2}{*}{$\begin{array}{l}p \text { value } \\
-\end{array}$} \\
\hline & 3 & 0.7 & 1 & 0.2 & \\
\hline OCS & 47 & 11.6 & 52 & 12.8 & 0.592 \\
\hline Antibiotics & 150 & 37.0 & 152 & 37.5 & 0.884 \\
\hline
\end{tabular}

Table 3 Post-index exacerbations and costs

\begin{tabular}{|c|c|c|c|c|c|}
\hline \multirow{2}{*}{$\frac{\text { Exacerbation measures }}{\text { Moderate-to-severe exacerbation }}$} & \multicolumn{2}{|c|}{ Aerobika OPEP } & \multicolumn{2}{|c|}{ Matched controls } & \multirow[t]{2}{*}{$p$ value } \\
\hline & & & & & \\
\hline Patients $(n, \%)$ & 75 & 18.5 & 104 & 25.7 & 0.014 \\
\hline Exacerbations per patient (mean, SD) & 0.23 & \pm 0.56 & 0.30 & \pm 0.55 & 0.099 \\
\hline Cost of exacerbation (mean, SD) & $\$ 2975$ & $\pm \$ 11,529$ & $\$ 6065$ & $\pm \$ 20,275$ & 0.008 \\
\hline \multicolumn{6}{|l|}{ Severe exacerbation } \\
\hline Patients $(n, \%)$ & 56 & 13.8 & 77 & 19.0 & 0.046 \\
\hline Exacerbations per patient (mean, SD) & 0.15 & \pm 0.40 & 0.21 & \pm 0.45 & 0.048 \\
\hline Cost of exacerbation (mean, SD) & $\$ 2838$ & $\pm \$ 11,516$ & $\$ 5871$ & $\pm \$ 20,134$ & 0.009 \\
\hline
\end{tabular}

matched controls $(p=0.008)$ (Table 3$)$. The mean cost of severe exacerbations per patient in the Aerobika OPEP cohort was also significantly lower than matched controls [\$2838 (SD $\pm \$ 11,516)$ vs. $\$ 5871$ (SD: $\pm \$ 0,134), p=0.009$, respectively] (Table 3 ). In the adjusted GLM model, the Aerobika OPEP cohort was associated with significantly lower mean cost of moderate-to-severe exacerbations per patient; the Aerobika OPEP group incurred 34\% lower costs than controls $(p=0.012)$ (Table 4$)$. The GLM estimating marginal effect of Aerobika OPEP on severe exacerbation costs did not converge due to the small number of observed severe exacerbation events.

The supporting data for oral corticosteroid and antibiotic drug usage in the hospital environment are reported in supplementary Table 5. The data, although only generated as secondary outcomes, are supportive of the exacerbation and cost data in that the proportion of patients was significantly lower in the Aerobika OPEP cohort for both classes of drugs.

\section{DISCUSSION}

This is the first real-world study to evaluate the benefits of an OPEP device on early (30-day) exacerbation outcomes, and adds to the literature by providing data on the potential benefits of Aerobika OPEP in a COPD population with chronic bronchitis. Despite the availability of a range of therapy options, exacerbations continue to be a common cause of healthcare resource use among COPD patients [14]. The mechanisms for protection from symptomatic exacerbations are not well understood, but improved sputum clearance, reduced variability in airway smooth muscle tone, and increased dyspnea thresholds are possible explanations [9]. The risk of experiencing subsequent exacerbations is 2-4 times higher in COPD patients with a prior exacerbation compared to those without a prior exacerbation [6]. Therefore, prevention is an important treatment goal $[3,5,19]$. OPEP devices, when used as 
Table 4 GLM model of moderate-to-severe exacerbation cost at 30 days

\begin{tabular}{|c|c|c|c|c|}
\hline Parameter & $\begin{array}{l}\text { Parameter } \\
\text { estimate }\end{array}$ & $\begin{array}{l}\operatorname{Exp} \\
(\beta)\end{array}$ & $\begin{array}{l}\text { Standard } \\
\text { error }\end{array}$ & $p$ value \\
\hline $\begin{array}{l}\text { Cost of moderate-to-severe exacerbation per Aerobika OPEP patient } \\
\text { (reference: controls) }\end{array}$ & -0.42 & 0.6570 & 0.1667 & 0.012 \\
\hline
\end{tabular}

Covariates included in the GLM were age groups, gender, payer type, CCI score category, comorbid conditions, pre-index observation period, and history of medication use

recommended, may help with sputum clearance, and hence provide a potential mechanism of protection from symptomatic exacerbations as described above.

Although our study was performed to generate hypotheses for future studies, our findings suggest that Aerobika OPEP may help reduce exacerbation events in COPD patients within the first 30 days. This trend was observed and consistent for both moderate-to-severe and severe exacerbations. Furthermore, the cost per patient of moderate-to-severe exacerbations and severe exacerbations was significantly lower in Aerobika OPEP patients than matched controls. Our regression model further confirmed this observed trend toward lower cost, and provides some internal validity that Aerobika OPEP may result in lower moderate-to-severe cost of exacerbation at 30 days in COPD patients with chronic bronchitis. Costs at 30 days are particularly relevant as providers and insurers continue to seek ways to reduce early re-hospitalizations in their patient population. Additional research is needed to confirm the benefits of Aerobika OPEP in a broader population, and future studies should assess exacerbations and costs beyond 30 days to confirm the long-term benefits of Aerobika OPEP.

There are a number of inherent limitations to all observational studies that should be acknowledged when interpreting results. Firstly, database studies can only establish associations and not cause-and-effect relationships. Secondly, the availability of Aerobika does not automatically confirm its regular use (typical prescribed use is for approximately 10 min twice a day [20]). Additionally, administrative databases like CDM do not provide the level of clinical detail as available in medical charts and it was not possible to confirm exacerbations using lung-function values or patient symptoms related to shortness of breath, and diagnoses relied on ICD-9 billing codes. Findings from this study may not be representative of other COPD populations (e.g., those not presenting at the hospital). Lastly, only medications dispensed in hospitals captured in the CDM database are available, so it was not possible to measure persistence or adherence of COPD medications over time.

Despite these limitations, the CDM hospital database is suited for conducting real-world studies in the COPD population because exacerbation events, especially severe events, are often treated in the hospital setting (e.g., emergency departments, outpatient clinics, and inpatient). Additionally, missing data are usually minimal for short-term study measures at 30 days and are likely to be missing at random; thus, our study sample was not likely biased or compromised in terms of systematically missing data. Further, our findings are strengthened by the comparison to a matched control group without evidence of treatment with any positive expiratory pressure or OPEP device at any time during the study period, and the use of PS matching to mimic randomization ensured similarity between the cohorts to reduce bias. Finally, the trend in lower moderate-to-severe exacerbation costs was also observed in our regression analysis, further strengthening the internal validity of our findings.

\section{CONCLUSIONS}

This is the first real-world study to evaluate the benefits of Aerobika OPEP in COPD patients with chronic bronchitis. Our findings demonstrate that the use of Aerobika OPEP post 
exacerbation may be associated with fewer exacerbations and lower exacerbation-related costs compared to COPD patients without a PEP or OPEP device within 30 days of index. Additional research is needed to further confirm the benefits of Aerobika OPEP in this patient population, over a longer study duration.

\section{ACKNOWLEDGEMENTS}

Sponsorship for this study and article processing charges was funded by Trudell Medical International. All named authors meet the International Committee of Medical Journal Editors (ICMJE) criteria for authorship for this manuscript, take responsibility for the integrity of the work as a whole, and have given final approval to the version to be published. All authors had full access to all of the data in this study and take complete responsibility for the integrity of the data and accuracy of the data analysis. The authors would like to acknowledge Debosree Roy of QuintilesIMS for writing support funded by Trudell Medical International.

Compliance with Ethics Guidelines. This article is based on a retrospective analysis of HIPAA compliant de-identified data and no IRB review was required.

Disclosures. Chakkarin Burudpakdee received compensation from Trudell Medical International. Arpamas Seetasith received compensation from Trudell Medical International. Dom Coppolo is an employee of Monaghan Medical Corporation, who marketed the Aerobika OPEP device in the US. Jason Suggett is an employee of Trudell Medical International. Patrick Dunne, Garry Kauffman, and Brian Carlin have nothing to disclose.

Data Availability. The datasets generated during and/or analyzed during the current study are not publicly available due to the commercially owned, proprietary nature of the datasets, but are available from the corresponding author on reasonable request.
Open Access. This article is distributed under the terms of the Creative Commons Attribution-NonCommercial 4.0 International License (http://creativecommons.org/licenses/ by-nc/4.0/), which permits any noncommercial use, distribution, and reproduction in any medium, provided you give appropriate credit to the original author(s) and the source, provide a link to the Creative Commons license, and indicate if changes were made.

\section{REFERENCES}

1. Ehteshami-Afshar S, FitzGerald JM, Doyle-Waters MM, Sadatsafavi M. The global economic burden of asthma and chronic obstructive pulmonary disease. Int J Tuberc Lung Dis. 2016;20(1):11-23.

2. Wilt TJ, Niewoehner D, MacDonald R, Kane RL. Management of stable chronic obstructive pulmonary disease: a systematic review for a clinical practice guideline. J Cardiopulm Rehabil Prev. 2008;28(2):147-8.

3. Hurst JR, Vestbo J, Anzueto A, et al. Susceptibility to exacerbation in chronic obstructive pulmonary disease. N Engl J Med. 2010;363(12):1128-38.

4. Agustí A, Edwards LD, Rennard SI, et al. Persistent systemic inflammation is associated with poor clinical outcomes in COPD: a novel phenotype. PLoS One. 2012;7(5):e37483.

5. O'Donnell DE, Aaron S, Bourbeau J, et al. Canadian Thoracic Society recommendations for management of chronic obstructive pulmonary disease-2007 update. Can Respir J. 2007;14(Suppl B):5B-32B.

6. Khakban A, Sin DD, FitzGerald JM, McManus B, Ng R, Hollander Z, Sadatsafavi M. The projected epidemic of COPD hospitalizations over the next 15 years: a population based perspective. Am J Respir Crit Care Med. 2016. [Epub ahead of print].

7. Shah T, Press VG, Huisingh-Scheetz M, et al. COPD readmissions: addressing COPD in the era of value-based healthcare. Chest. 2016. [Epub ahead of print].

8. O'Donnell DE, Parker CM. COPD exacerbations. 3: pathophysiology. Thorax. 2006;61(4):354-61.

9. Balter MS, La Forge J, Low DE, et al. Canadian guidelines for the management of acute 
exacerbations of chronic bronchitis. Can Respir J. 2003;10(Suppl B):3B-32B.

10. Perera PN, Armstrong EP, Sherrill DL, et al. Acute exacerbations of COPD in the United States: inpatient burden and predictors of costs and mortality. COPD J Chron Obst Pulm Dis. 2012;9(2):131-41.

11. Puhan MA, Scharplatz M, Troosters T, et al. Respiratory rehabilitation after acute exacerbation of COPD may reduce risk for readmission and mortality-a systematic review. Respir Res. 2005;6(1):1.

12. From the global strategy for the diagnosis, management and prevention of COPD, global initiative for chronic obstructive lung disease (GOLD). 2017. http://goldcopd.org.

13. Svenningsen S, Paulin G, Wheatley A, Pike D, Suggett J, McCormack D, Parraga G. Oscillating positive expiratory pressure (oPEP) therapy in chronic obstructive pulmonary disease and bronchiectasis. Eur Respir J. 2014;44(Suppl 58):P3679.

14. Svenningsen S, Paulin GA, Sheikh K, Guo F, Hasany A, Kirby M, Etemad Rezai R, McCormack DG, Parraga $\mathrm{G}$. Oscillatory positive expiratory pressure in chronic obstructive pulmonary disease. COPD J Chron Obstr Pulm Dis. 2016;13(1):66-74.

15. Johnson ML, Crown W, Martin BC, Dormuth CR, Siebert U. Good research practices for comparative effectiveness research: analytic methods to improve causal inference from nonrandomized studies of treatment effects using secondary data sources: the ISPOR Good Research Practices for Retrospective Database Analysis Task Force Report-part III. Value Health. 2009; 12(8):1062-73.

16. Nazir SA, Erbland ML. Chronic obstructive pulmonary disease. Drugs Aging. 2009;26(10):813-31.

17. AbuDagga A, Sun SX, Tan H, Solem CT. Exacerbations among chronic bronchitis patients treated with maintenance medications from a US-managed care population: an administrative claims data analysis. Int $\mathrm{J}$ Chron Obstr Pulmon Dis. 2013;8(1):175-85.

18. Cost H. Utilization project (HCUP). Overview of the nationwide inpatient sample, (NIS). http://www. hcup-us.ahrq.gov/databases.jsp. Accessed Feb 2009.

19. Andersson F, Borg S, Jansson SA, Jonsson AC, Ericsson $\AA$, Prütz C, Rönmark E, Lundbäck B. The costs of exacerbations in chronic obstructive pulmonary disease (COPD). Respir Med. 2002;96(9):700-8.

20. Trudell Medical International. Aerobika* oscillating positive expiratory pressure therapy system. Instructions for use. 2013. https://www.trudellmed. com/sites/trudellmed.com/files/pdf/consumer/opep_ ifu.pdf. Accessed Jan 12, 2017. 